\title{
Professional socialization of children in virtual museum space
}

\author{
Marina Grechitaeva $^{1^{*}}$, Irina Oleynikova $^{1}$, and Marionella Kolokoltseva $^{2}$ \\ ${ }^{1}$ Belgorod State National Research University, 308015, Belgorod, Russia \\ ${ }^{2}$ Astrakhan State University, 414056, Astrakhan, Russia
}

\begin{abstract}
The article analyzes the possibilities of competitive and exhibition activities in the virtual museum space for the development of professionally oriented interests and inclinations in children aged 7-14 years. A set of the most effective methods, techniques and forms of organizing competition and exhibition activities has been determined, a specially developed diagnostic toolkit has made it possible to analyze the experimental data obtained as a result of the use of empirical research methods: observation and survey. It was revealed that schoolchildren aged 7-14 are at different stages of professional maturity, from the stage of awakening (younger students) to the stage of professional socialization (younger adolescents). Experimental data have confirmed that competition and exhibition activities contribute to the development of creative thinking, self-actualization of the personality of schoolchildren. The huge educational potential of the competition and exhibition activity has been confirmed. The developed program of competitive and exhibition activities of a chemical orientation, contributing to the formation of professionally oriented interests and inclinations in children aged 7-14 years, will be useful to teachers, museum specialists.
\end{abstract}

Keywords: virtual museum, professional socialization, methodology.

\section{Introduction}

Problems of professional socialization of the individual, due to their insufficient elaboration, attract more and more attention of researchers in various scientific specialties. And the constant change in the objective conditions in which self-determined individuals find themselves, all the more increases the interest in these problems [1]. So, in the context of a pandemic that led to a rapid growth in the digitalization of education, teachers are especially acutely faced with the questions of creating a favorable environment for the professional socialization of schoolchildren. And this environment becomes the virtual space of specially equipped structures aimed at conducting career guidance work. The subjective conditions of professional socialization indicate the use of creative activities that bring the child joy, satisfaction in the process of free creation of a creative product. An important means of selfactualization of the personality is exhibition activity, during which the child has the opportunity to demonstrate the product of his creative activity, to present it. The involvement

\footnotetext{
*Corresponding author: grechitaeva@ bsu.edu.ru
} 
of a student in competition and exhibition activities in the virtual space of specialized structures can become a successful mechanism for professional socialization, but it needs detailed study.

The research problem is as follows: how to use the potential of competition and exhibition activities for the professional socialization of a student.

Research object: professional socialization of a schoolchild.

Subject of research: competition and exhibition activities as a means of professional socialization of a schoolchild.

Research hypothesis: the process of professional socialization of a student in the process of competitive and exhibition activities will be successful if:

- to correlate the content of the competition and exhibition activities with the actual needs and interests of the individual; participation in it will ensure the satisfaction of the student's need for recognition, increase his social status, and allow him to feel the demand for interesting socially useful work; the topics of the contests will be varied;

- competition and exhibition activities will stimulate the development of creativity, imagination, non-standard thinking, interest in the subject and the exhibition itself as a space of self-actualization and self-realization in creative activities;

- to ensure the unity of lesson and extracurricular activities, which are the source of ideas.

The natural science collections of universities, the structural units that are their custodians, as well as the virtual museum space, are intended for the environmental education of the individual, as well as the development of professionally oriented interests and inclinations of a fairly wide range of visitors. One of the main groups of such visitors is children under the age of 14 , who, according to D. Super's psychological theory of professional maturity [2], are at the "awakening stage", or at the stage of professional socialization [3].

The relevance of this study is due to the need to introduce into the educational process new ways of forming and developing a personality, creative thinking, abilities for selfdetermination and self-realization.

The aim of the work is to develop a methodology for enhancing the interest of the children's audience in the natural sciences, in particular chemistry, supporting gifted children by means of competition and exhibition activities in a virtual museum space.

\section{Materials and methods}

The research was carried out on the basis of the exposition and exhibition center "Nature of Belogorya" of the Belgorod State National Research University. The experiment involved 18 schoolchildren aged (7-14 years). When choosing diagnostic tools for determining the level of professional socialization of schoolchildren, we relied on the works of D. Super [3], Makarova S.N. [2], G.S. Prokhorov [4]. According to D. Super's psychological theory of professional development, at this age children are at the "awakening stage", or at the stage of professional socialization. During this period, the child develops a wide range of cognitive interests and abilities, forms ideas about the world of professions, and develops propensities for one or another type of professional activity.

The criteria for assessing the level of professional socialization of schoolchildren in the competitive and exhibition activities of a chemical orientation were determined: motivational-need, cognitive, and activity-practical. For our study, their indicators were specified:

1. Motivational-need-based - the level of interest in labor, cognitive and professional activities, attitude to the work of people and professions in the field of natural science, the desire to get a profession in this area is determined, includes indicators: the presence of interest in labor, professional, cognitive, competitive exhibition activities, experimentation, 
actions with substances; attitude to human labor and professions in the natural sciences; desire to master a profession that requires knowledge in the field of chemistry.

2. Cognitive - assessment of students' knowledge about the world of work and professions, ideas about their own qualities and capabilities, the ability to independently assess their knowledge at a certain level, includes the following indicators: knowledge about the world of work of people; knowledge about the world of professions of people associated with knowledge in the field of chemistry, experimenting with substances.

3. Activity-practical - an assessment of the manifestation of industriousness, discipline, activity, conscientiousness, responsibility in educational and cognitive work, expressed in the following indicators: the manifestation of industriousness, independence in the process of experimentation, actions with substances; activity, conscientiousness, responsibility in research and competition and exhibition activities.

Solving the problem of developing diagnostic tools for our research aimed at identifying the level of professional socialization among schoolchildren, including the development of a cognitive interest in the field of natural science knowledge, a propensity for experimentation, actions with substances as one of the components of interest in the field of chemistry, selfactualization in the competition and exhibition activities, diagnostic methods were selected: the method of unfinished sentences, observation (motivational-need criterion), testing, the method of unfinished sentences (cognitive criterion), analysis of the products of competition and exhibition activities (activity-practical criterion).

For diagnostics based on the motivational-need criterion, the method of unfinished sentences was used. Schoolchildren were asked to answer questions about the importance of work, about their future profession, about the motives of their choice.

Diagnosis by cognitive criterion was carried out using testing based on the methodology "Do you know the profession?" S.V. Yakovleva [5], concretized for the subject of our research and the method of unfinished sentences. The students were asked to answer the following questions.

1. What is the name of the profession whose representative is engaged in the study of chemical processes occurring in nature and carried out in laboratory conditions?

a. Chemist

b. Chemical analysis laboratory assistant.

c. Research chemist (1 point).

2. What does a chemical technologist do?

a. Develops new or improves old production processes of any product.

b. Manufactures chemicals.

c. Conducts chemical experiments (1 point).

3. What is the name of the profession whose representative works in the production, storage and sale of medicinal products?
a. Pharmacist.
b. Doctor.
c. Nurse (1 point).
4. A representative of what profession teaches chemistry to schoolchildren?
a. Chemist
b. Laboratory assistant
c. Chemistry teacher (1 point).
5. Choose a profession whose representative does not need to know chemistry?
a. Chemical analysis laboratory assistant.
b. Environmental chemist.
c. Biochemist.
d. Software engineer.
e. Pharmacist. 
f. Doctor (1 point).

Test results are evaluated as follows:

high level -5 points;

average level - 4-2 points;

low level - 1-0 points.

The study of the level of professional socialization in schoolchildren according to the cognitive criterion was also carried out using the method of unfinished sentences.

Supplement the proposals with your views and attitudes towards work and professions.

I believe that people should work because... .

Labor should bring people... because ...

I would like to choose a profession ... because ... .

Knowledge of chemistry is necessary for representatives of such professions as ..., these professions are important for .... .

High level. The student understands that work should benefit people, a sense of selfsatisfaction. The student has certain professional interests, ideas about professions related to knowledge of chemistry, an understanding of their importance is manifested.

Average level. The student presents labor activity as a means of achieving material wellbeing. The student has certain professional interests, certain ideas about professions related to knowledge of chemistry, but there is no understanding of their importance.

Low level. The student has no idea of the meaning of labor for himself, for those around him. There is a lack of conscious professional interests and understanding of professions related to knowledge in the field of chemistry.

According to the results of diagnostics at the ascertaining stage of the experiment, three levels of professional socialization of schoolchildren in the competitive and exhibition activities of a chemical orientation were determined: high, medium, low.

1. High level. Students have a conscious understanding of the work activity of people, they know the main professions associated with knowledge of chemistry, their characteristics, they understand and realize the importance of this profession for people. They have a positive and respectful attitude towards the labor activity of adults and their specialties. Schoolchildren are interested in chemical-oriented competition and exhibition activities, they want to acquire in the future some kind of profession related to chemistry, they can explain why they made such a choice. Schoolchildren actively participate in competition and exhibition activities, show diligence in completing assignments, and formulate the results of the work done in a high-quality manner.

2. Average level. Students have an understanding of the work activity of people. They can name the professions associated with knowledge in the field of chemistry, but they do not quite correctly know their main features, they do not always correctly understand the importance of a particular profession for people. They relate well to the daily work activities of seniors and their professions, but in relation to competition and exhibition activities, their interests require greater stability and depth. Schoolchildren dream of getting some kind of profession in the future, but they cannot always explain their choice. Fragmentally show interest in professions related to knowledge in the field of chemistry. They have little initiative and are able to participate in work only when adults require it. They faithfully carry out assignments, but do not show activity and creativity in competition and exhibition activities.

3. Low level. Students have insignificant and vague ideas about the work activity of people. They are not able to characterize the main features of the professions associated with knowledge in the field of chemistry, they do not understand the importance of these professions for people. Schoolchildren show little interest in educational and professional activities, as well as in the labor activity of adults and in their professions. When participating in competition and exhibition activities, they require constant supervision by adults. Tasks 
are not carried out conscientiously enough, they do not have the simplest skills to formulate the results obtained.

To identify the level of professional socialization of schoolchildren in the competitive and exhibition activities of a chemical orientation, we conducted a study based on educational institutions of the Astrakhan region and the exposition and exhibition center "Nature of Belogorya" of Belgorod State University. The experiment involved 26 students aged 7-14 years

\section{Results and discussion}

As a result of summarizing the data for all diagnostics, it was revealed that $6(23.1 \%)$ people showed a high, 15 people (57.7\%) - average, 5 people (19.2\%) - a low level of professional socialization in competitive exhibition activities of chemical orientation.

Summing up the results of this study, we note that when performing the test, most of the schoolchildren showed good knowledge of the professions related to chemistry: doctor, pharmacist and laboratory assistant in chemical analysis. Difficulties were in defining such professions as biochemist and chemical technologist.

The method of unfinished sentences made it possible to determine the level of formation of a respectful attitude to work, the presence of interest in specialties in the chemical, biochemical, medical industries, and the motivation for success in performing work. According to schoolchildren, a person must work in order to do his job well and with high quality. After clarifying questions, many referred to the fact that it is necessary to receive some kind of monetary reward for a high-quality work performed. Some guys ended the next sentence like this: pleasure, health, salary, food, income.

Analysis of the products of competition and exhibition activities based on motivational and activity criteria showed an average level of professional socialization.

Based on the data obtained, a program of remote chemical contests was developed: "Artist's Workshop" (homemade paints), "My own perfumer" (creation of perfume and soap), "Experiments with yummy" (honey, sweets, etc.), " Children's Bar "(making drinks), Beauty of Minerals "(growing crystals), aimed at increasing the level of professional socialization, showing diligence, discipline when performing competition tasks, awakening interest in professions related to the study of chemical processes, actions with substances and materials, experiences and experiments.

After the implementation of the program developed by us, a control experiment was carried out using the same methods as at the ascertaining stage, with some changes in the content of the test items. A positive change in the level of professional socialization of schoolchildren in the competitive and exhibition activities of a chemical orientation was noted according to all the selected criteria. Our results indicate that our proposed program was effective.

The schoolchildren have expanded their ideas about the professions associated with knowledge of chemistry, an understanding of their importance has emerged, a desire to study chemicals, processes, experimenting, and in the future - to master one of these professions has appeared.

Thus, those schoolchildren for whom we initially identified a low level of professional socialization rose to the average, and those children who had an average level raised it to a high level

Consequently, a specially developed program of competitions of chemical orientation in a remote form, including actions with substances and materials, experimentation, setting up experiments, have an effective impact on increasing the level of professional socialization of schoolchildren in competition and exhibition activities of chemical orientation. 


\section{Conclusion}

According to the results of the study, it can be stated:

- the huge potential of competition and exhibition activity for the successful professional socialization of schoolchildren has been confirmed. Competitive and exhibition activities, involving the study of chemicals and actions with them, experimentation, setting up experiments, registration of the results of their activities, allows students to increase their interest in the study of chemistry, which is an essential component of professional selfdetermination and self-realization of the individual in the chosen profession;

- the conditions of competitive and exhibition activities make it possible to implement remote forms of organizing the educational process aimed at professional socialization of a chemical orientation;

- the developed program will be useful for teachers, teachers, specialists of exposition and exhibition centers for organizing activities aimed at the professional socialization of schoolchildren.

- the use of the means and methods chosen by us contributed to the emergence of students' knowledge of professions related to knowledge in the field of chemistry.

Schoolchildren have expanded their ideas about their own qualities and capabilities, they learned to assess their business qualities, they have an interest in labor, educational and professional activities of a chemical orientation, a desire to master one of these professions, a positive attitude towards the work of people in the field of theoretical and applied chemistry has been formed. The process of competition and exhibition activities showed diligence, discipline, activity, conscientiousness, responsibility.

\section{References}

1. A.V. Weisburg, Professional orientation, 1, (2014)

2. S. N. Makarova, Almanac of modern science and education, 4, 2, (2008)

3. D.E Super, The psychology of career, (Harper\&Brothers, 1957) 2016)

4. G. S. Prokhorov, Fundamentals of vocational guidance for schoolchildren, (Academy,

5. S. A. Yakovleva, Primary School, 29, (2011) 